\title{
Humanization and Macroergonomics: An Analysis in the Billing Sector of a University Hospital in Paraná
}

\author{
Larissa de Oliveira Matia LEITE ${ }^{1}$ Alexandre Minoru SASAKI, Rosimeire Sedrez \\ BITENCOURT, Maria Lucia Miyake OKUMURA and Osiris CANCIGLIERI \\ JUNIOR \\ Pontifical Catholic University of Paraná,Brazil - Polytechnic School Industrial and \\ Systems Engineering Graduate Program - PPGEPS/PUCPR
}

\begin{abstract}
The humanization of organizations is a trend in companies that have a vision of the future aligned with the needs of the market. In the health area, this humanization should not be limited to its users, but include the employees involved in the work system. The human aspect and its relations with the work system is a focus of studying ergonomics, which in its macroergomic approach aims at integrating organization-man-machine systems into a sociotechnical and participatory context. This study aims to apply the macroergonomic approach with health workers in order to propose and implement improvements; evidencing the importance of their involvement in better acceptance of the proposed improvements generating greater satisfaction. To this end, a study was conducted in the Billing sector of a Brazilian Hospital. Ergonomic demands were identified in a participatory way through the Macroergonomic Analysis of Work (MAW) method, proposed in [1]. The results were tabulated and divided into constructs: Environment, Biomechanical, Cognitive, Work Organization, Risk, Company and Discomfort/Pain. After one year, a new macroergonomic evaluation was carried out and the improvements implemented included the concept of the sociotechnical system, which were: i) acquisition of new computers; ii) implementation of a new computational system and; iii) implementation of changes in the form of sector management. The results showed an increase of up to $40 \%$ in satisfaction with the improvements implemented in the Biomechanical and Organizational constructs, indicating that the application of participatory ergonomics and macroergonomics was fundamental for the changes made to increase satisfaction in aspects of the work performed by them. Finally, this research highlights the importance of employee involvement in sociotechnical analysis for the humanization of organizations and it is suggested for future studies the proposition of improvements related to the Environment and Cognitive constructs and pain/discomforts.
\end{abstract}

Keywords. Humanization; Ergonomics; Macroergonomics; Improvements; Satisfaction.

\section{Introduction}

In the organizational context, the humanistic approach of administration aims at the care, integration and harmonization of different stakeholders, based on philosophical humanism, considering workers as individuals and as people who relate to the work environment [2]. Similarly, ergonomics is a scientific discipline that aims to optimize human well-being and the overall performance of the work system, based on human interactions with other elements that make up a work system [3]. In its macroergonomic approach, ergonomics consider the worker's participation in the integration of

\footnotetext{
${ }^{1}$ Corresponding, Author, Mail: leitelarissa11@gmail.com; larissa.leite@pucpr.edu.br.
} 
organization-man-machine systems [1]. Therefore, despite being disciplines of different areas of study, both focus on the study of the human and their relationships in the work environment.

Collaboration between disciplines from different areas in order to solve unstructured problems is part of the transdiciplinary research process [4]. The research of transdisciplinary engineering uses not only disciplines from engineering (as is the case of ergonomics), but also of disciplines from other areas, aiming at solving problems making use of profissional of various specialties and stakeholders [5].

Thus, considered for the realization of this study the participation of workers as a central point for humanization and macroergonomics in the context of the billing sector of University Hospital located in the city of Curitiba in the state of Paraná in Brasil.

The departament in question is responsible for detailing all the costs that the hospital obtained with the treatment of its patients within the conformities stipulated by the Brazilian health system. The billing department must follow the payment pattern stipulated by the public health system in Brazil, so that the hospital receives funds for the continuous treatment of patients. The challenge for the billing sector is to align the costs of maintaining the hospital with the value provided by the Health System. In view of this, the sector is constantly under pressure to improve its work processes and the performance of its workers, so that all the necessary value for the maintenance of the hospital is provided by the Health System.

Therefore, this study aims to apply the macroergonomic approach with a view to humanizing the environment of health workers in order to propose and implement improvements; evidencing the importance of their involvement in better acceptance of the proposed improvements generating greater satisfaction.

The article is organized as follows, in section 1, the definitions of humanization, ergonomics and macroergonomic are described. Section 2 presents the methodology used in the study. Section 3 presents and discussed the results of the study. Finally, section 4 contains conclusions and suggestions for future studies.

\section{Background}

This section presents a humanization briefing (section 1.1) and the description of the concepts related to ergonomics (section 1.2), the two disciplines considered in this study.

\subsection{Humanism}

Humanism is a guiding perspective on human needs and oriented towards the development of human virtue. Concerns about the structuring of social life based on human characteristics, assuming that everyone has the same rights and must reach everyone [6] [7].

Humanistic organizations are guided by humanistic concepts, such as social group, group dynamics, motivation, communication, leadership, teamwork, seeking to develop individual motivations of employees and reduce gaps between the organizational and individual objectives of employees. These organizations promote the integration between the objectives of different stakeholders, promoting the balance of qualitatively desirable results [8] [7].

The humanistic approach of the Administration is ruled in a more democratic and humanized organizational administration, which does not block individual growth and self-development of workers, emphasizing the human condition in work [8] [6]. 


\subsection{Ergonomics}

According to [9], "Ergonomics (or human factors) is the scientific discipline concerned with the understanding of interactions among humans and other elements of a system". Its objective being the optimization of human well-being and the overall performance of the system [3].

The study of ergonomics is formed by the man-machine-environment system, being the man any person, or people, responsible for performing a work; the machine, and can be both physical and cognitive; and the environment, which can be internal, where the work takes place, or external [10].

Ergonomics in its man-system interface technology consists of five interfaces, including man-machine interface or hardware-ergonomics, human-environment interface or environmental ergonomics, human interface-software or cognitive ergonomics, man-work interface or ergonomics of work design and, organizational ergonomics or macroergonomics [11].

Macroergonomics is the ergonomic approach that considers the man-organization relationship and external factors that influence this relationship, and therefore is the most comprehensive of its approaches.

\subsubsection{Macroergonomics}

Macroergonomics, defined by Hendrick, works in order to integrate the organizationman-machine systems. This approach considers the human factor within the organization and external factors that influence its work, encompassing socio-technical characteristics of the organization, considering characteristics of the work system, external system and personal system. It makes use in its application of participatory ergonomics, providing with the involvement of employees to improve productivity, increased satisfaction, improvement in safety at work and in the company, causing reduction of errors and accidents [12] [10].

Based on the application of the concepts of humanization and ergonomics, this article proposes the use of worker participation as a central point in the application of humanization and macroergonomics in order to propose and implement improvements in the study sector, increasing worker satisfaction.

\section{Methodology}

The study is based on the billing sector of a University Hospital in the city of Curitiba Paraná, Brazil, in which two samples of 17 employees participated in the study, corresponding to $89 \%$ of the total number of employees in the departament, in 2018 and 2019. In this case study, information is collected and analyzed and worked qualitatively and quantitatively in order to apply the MAW method.

\subsection{Macroergonomic Analysis of Work (MAW)}

The Method of Macroergonomic Analysis of Work (MAW) was proposed by [1] to identify, monitor and modify participatory any activity that puts at risk the quality of life of the worker. With the application of MAW, we have an analysis of the work both from the point of view of the ergonomics (specialist responsible for the application of ergonomics) and of workers, who participate directly or indirectly. 
The method consists of six stages, which are iterative and not necessarily linear, being: 0 - project launch, 1 - ergonomic survey or appreciation, 2 - ergonomic diagnosis or situation analysis, 3 - proposal of improvement solutions, 4 - validation solutions and 5 - ergonomic detail [1]. Phase 5 was not contemplated in this study.

\subsubsection{Project launch}

As a way of launching the project, a meeting was held with the board of the hospital in which the macroergonomic analysis of the work was agreed.

\subsubsection{Ergonomic appreciation and diagnosis}

To survey the ergonomic demands of the billing sector, an interview was conducted spontaneously and voluntarily with a convenience sample of 7 employees. Based on results obtained with the interviews, direct observation of employees in their work post and in the opinion of an ergonomics specialist, satisfaction, importance and discomfort/pain questionnaires were elaborated.

The questionnaires were composed of questions regarding the Environment, Biomechanical, Cognitive, Work Organization, Risk and Enterprise (EBCORE), and discomfort/pain, and the answers were given through a continuous line.

This method uses questions in its questionnaires with a continuous line of 15 $\mathrm{cm}$ so that respondents mark an $\mathrm{x}$ at the location of the line they think is most correct for the question. At the ends of each line are words that guide the formation of a continuous scale. At the left end, indicating the value zero, are the words unsatisfied, unimportant or low, with each word used in the satisfaction, importance and discomfort/pain questionnaires, respectively. At the right end, there are the words satisfied, important and very much, with each word used in the satisfaction, importance and discomfort/pain questionnaires, respectively [13].

The scale indicates that the closer the answer is to $0 \mathrm{~cm}$, the less satisfied, the less important or the lower the score for the corresponding question requirement. Whereas, the closer the answer is to $15 \mathrm{~cm}$, the more satisfied, the more important or higher the grade for the requirement of the question corresponding to the answer. The $7.5 \mathrm{~cm}$ indicates the average value.

With the help of the Software SPSS ${ }^{\circ}$ version 22.0.0.0, the Cronbach Alpha test was performed for all constructs, aiming to analyze the consistency of the data obtained with the answers of the questionnaires, obtaining a value of 0.805 , characterizing in a high reliability of the data.

Graphs were sketched using Microsoft Excel Software ${ }^{\circledR}$ version 1804 referring to EBCORE constructs, considering the average values of each question for importance, satisfaction and pain.

Cluster analysis (partitioning of a dataset into smaller subgroups that are significant) was performed through simulations with the aid of Minitab Software ${ }^{\circledR}$ version 17.1.0, in order to identify the type of link that best represents the concepts of the study through the form of a dendogram [14].

\subsubsection{Proposals and validation of improvement solutions}

Based on the results obtained in the graphs and cluster analysis, it was possible to perform analysis of the data obtained with the interviews, to make the diagnosis of demands and thus the proposals for improvements. The proposals for improvements were 
presented to the hospital board in order to promote its validations and applications. [15] represented in detail the methodologies for implementing steps $0,1,2,3$ and 4 and their respective results.

\subsubsection{Ergonomic diagnosis}

Because it is an iterative method that allows reassessments at any time, it was recommended to reevaluate the perception of employees in the sector regarding the proposed improvements. After one year of the applications of steps from 0 to 4 , the discomfort/pain questionnaires and satisfaction in relation to the EBCORE constructs were reapplied. The data obtained with the application of the questionnaires also obtained some consistency, with a value of 0.663 , but this consistency for being below the value 0.7 , indicates that the data obtained from the questionnaires are not as reliable as those of the previous year.

\section{Results}

\subsection{Participation: a focal point}

Because it is a sector highly pressured in the search for performance improvement, it was necessary to evaluate, from the point of view of workers, how impactful the changes made in the hospital affected the way work is performed. Participation, then, was not fundamental for this evaluation. The reapplication of step 2 of the MAW method through satisfaction and discomfort/pain questionnaires and the comparison between the values of the 2018 and 2019 EDIs (Ergonomic Demand Index) were ways to perform a humanistic management of the sector and validate the modifications.

\subsection{Proposition and application of solutions}

In his 2018 study, [15] performed ergonomic appreciation and diagnosis (stages 1 and 2 of the MAW) of the sector, presenting data obtained with the performance of interviews with employees for the construction of The EDIs in the applications of the questionnaires of satisfaction and discomfort/pain and, later, being carried out in-depth analyses based on statistical techniques and references in the area of Ergonomics. Based on the analysis, suggestions for improvements to the sector were proposed and the direction of the hospital was presented.

In 2019, the hospital underwent management changes, changes that affected the way work was carried out in the Billing sector. Thus, after the implementation of the changes, satisfaction questionnaires and discomfort/pain were applied in order to identify possible improvements in The EDIs.

\subsubsection{Comparison of satisfaction between the years 2018 and 2019}

The changes that occurred in the hospital generated three changes for the sector, which were: i) acquisition of new computers; ii) implementation of a new computational system and; iii) implementation of changes in the form of sector management.

i) Acquisition of new computers: new computers were purchased that were compatible, in terms of processing, to programs that are utillized by the sector for account billing; 
ii) Implementation of a new computational system: in addition to the systems offered by the Brazilian health system, the hospital uses an internal system. The internal hospital system was exchanged for one that integrated the various areas of the hospital;

iii) Implementation of changes in the form of sector management: with the change of management of the hospital, the management of the sector, which was previously made by the financial area, passed to be carried out by the quality area of the hospital.

In the satisfaction questionnaires applied in both years, values were considered on a scale between 0 , which considers the total unsatisfaction of the employee in relation to the EDI, to 15, which considers the total satisfaction of the employee in relation to the EDI. EDIs that obtained average responses from employees with values below 7.5 would be considered for EDIs that deserved attention. In 2018, EDIs that obtained low averages were the target of possible improvement proposals and, in 2019, they were analyzed if the improvements made in the previous year affected EDIs that needed attention.

For questionnaires referring to the Cognitive construct in both years, values (or equals) to 0 considered less and values close (or equal) to 15 considered very much. Averages below 7.5 are not necessarily considered bad and EDIs are worthy of attention, with each EDI in particular to understand the average below 7.5 is positive or negative for the EDI.

Table 1 presents the mean values of the EDIs for the EBCORE constructs, with the data of [1] for 2018. Note that the satisfaction of employees regarding several EDIs had changes in values, due to the changes made, and the amount of EDIs with averages below 7.5 decreased. The constructs Biomechanical, Cognitive and Work Oganization present greater differences in their values of means, and the Cognitive construct detailed in 3.2.1.2.

Table 1. EDIs averages per construct for the years 2018 and 2019.

\begin{tabular}{clcc}
\hline Costruct & \multicolumn{1}{c}{ EDI } & Average EDI 2018 & Average EDI 2019 \\
\hline \multirow{5}{*}{ Environment } & 5.9 & 6.3 \\
& Temperature & 5.8 & 9.5 \\
& Air quality & 6.0 & 5.1 \\
& Nleaning quality & 7.0 & 7.2 \\
& Noise & 6.1 & 6.2 \\
\hline \multirow{2}{*}{ Biomechanical } & Post physical space & 10.1 & 8.1 \\
& Posture to do the job & 8.2 & 10.1 \\
& Furniture quality & 4.7 & 11.1 \\
& Computer suitability & 3.8 & 9.9 \\
\hline & Physical effort & 5.8 & 123 \\
& Mental effort & 14.2 & 8.6 \\
& Monotonous work & 5.5 & 9.4 \\
& Limited work & 6.1 & 5.0 \\
& Creative work & 6.6 & 5.7 \\
& Dynamic work & 9.6 & 7.1 \\
& Stimulating work & 8.7 & 11,6 \\
& Complex work & 12.8 & 12.5 \\
& Repetitive work & 10.7 & 1,9 \\
& Tiring work & 12.8 & 13.7 \\
& Work involves responsibility & 13.9 & 9.4 \\
& Appreciation for work & 9.7 & 9.2 \\
& Autonomy at work & 11.1 & 11.3 \\
& Stressful work & 12.3 & 7.5 \\
& Psychological pressure by superiors & 8.9 & 9.3
\end{tabular}




\begin{tabular}{clcc} 
& Like work & 13.0 & 12.3 \\
& Workload & 12.3 & 10.8 \\
\hline \multirow{5}{*}{ Number of intervals } & 12.2 & 11.5 \\
& Adequacy of the Hospital System & 4.3 & 8.6 \\
& Adequacy of the Health System & 7.4 & 9.1 \\
Corganization & Computer adequacy & 3.8 & 9.9 \\
& Uniforms availability & 3.1 & 9.9 \\
& Relationship with other & 6.0 & 8.8 \\
& sectors/professionals & & 11.9 \\
& Bank of hours & 10.5 & 7.8 \\
& Adequacy of workload to completion of & 6.8 & 8.9 \\
goals & & 7.8 \\
\hline \multirow{5}{*}{ Risk, Company } & 10.1 & 9.7 \\
& Transportation to work & 6.6 & 4.1 \\
\hline
\end{tabular}

\subsubsection{Satisfaction in Biomechanical constructs and Work Organization}

As presented in Table 1, the Biomechancical and Work Organization constructs had significant variations in the averages of their EDI between 2018 and 2019. Thus, Graph 1 presents the percentage difference between the two years of application of satisfaction questionnaires, highlighting the changes that occurred in the sector due to the implementation of the changes.

Comparison Satisfaction Biomechanical and Work Organization Constructs

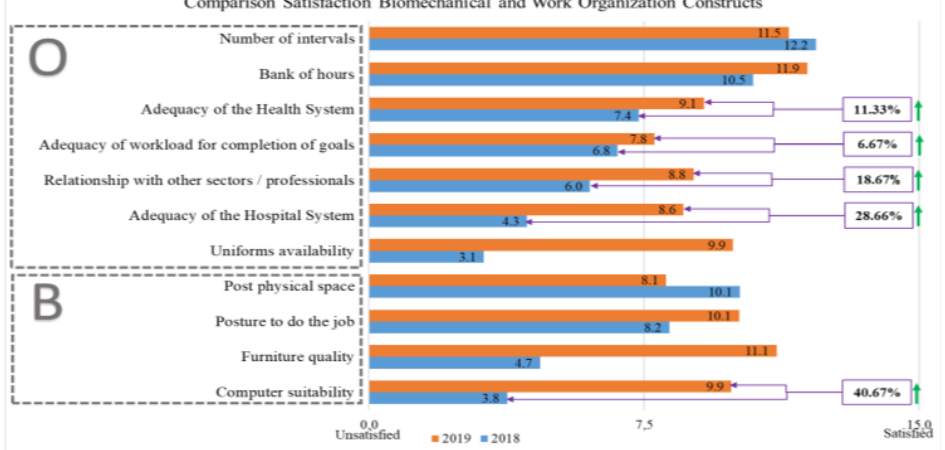

Graph 1. Comparing stisfaction to the Biomechanical and Work Organization for the years 2018 and 2019.

From Graph 1, it is pointed out that the satisfaction regarding the computer suitability is the one that obtained the most significant improvement, with a $40.67 \%$ difference in their satisfaction. Next, there is a difference of $28.66 \%$ in the satisfaction of the adequacy of the Hospital System, with the exchange of the system used internally in the hospital. Satisfaction in relation to the relationship with other sectors/professionals obtained a difference of $18.67 \%$ and, $11.33 \%$ difference in the adequacy of the Health System, this reflection of the exchange of computers for more appropriate use. Finally, the adequacy of the workload for completion of goals obtained a difference of $6.67 \%$ in satisfaction, indicating that the changes in computers and in the system used by the hospital reflected so that the time to complete the goals became more appropriate, thus increasing satisfaction. Thus, Graph 1 reflects the opinion of employees that with the changes made to satisfaction and performance during the work performed by them, they increased.

\subsubsection{Opinion in the Cognitive construct}

The analysis of the difference in opinion of workers regarding the Cognitive construct becomes necessary, since the averages of the EDIs suffered variations between 2018 and 
2019. Cognitive requirements in workers have increased due to changes in work [16], as occurs in the present study. To understand how the way workers see their work was modified by the changes, The Graph 2 was elaborated.

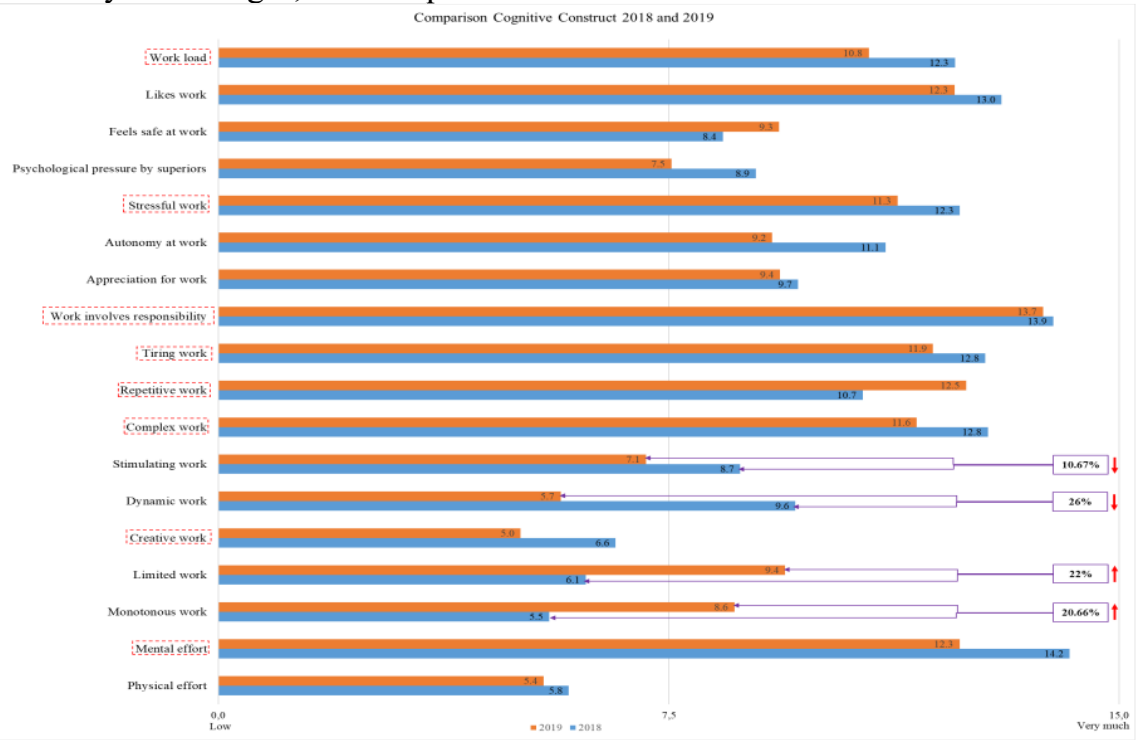

Graph 2. Comparison of opinion for the Cognitive construct for the years 2018 and 2019.

Graph 2 points out the percentage difference between the opinions of the workers about the EDIs of this construct. Between 2018 and 2019 some EDIs deserve attention and require an in-depth investigation for the difference found, they are dynamic work, stimulating work, limited work and monotonous work.

Comparing the averages of the EDI dynamic work, it is noted that between 2018 and 2019 employees began to consider the work much less dynamic, from an average of 9.6 in 2018 to an average of 5.7 in 2019. For the EDI stimulating work, there was a reduction of $10.67 \%$ in how stimulating employees consider the work, requiring a deepening of the reason that caused the change of stimulus in the work developed by employees. In 2018 the collaborations considered the work much less limited, with an average of 6.1, but in 2019 the average for this EDI increased, becoming 9.4, a difference of $22 \%$ that also deserves an in-depth investigation.

According to [10], works that are very repetitive and with prolonged activities end up being unmotivating and monotonous, so the work developed by employees in the sector can be considered monotonous. Although in 2018 employees did not consider the monotonous work, an average of 5.5, however, in 2019 the work began to be considered monotonous, with an average of 8.6 , pointing to a difference of $20.66 \%$ in monotony. Thus, it is necessary to evaluate what workers understand by monotony.

In both years the work involves a lot of responsibility and great psychological pressure by superiors because all patient data should be thoroughly evaluated so that there are no errors in the accountability of the hospital. In addition, there is a lot of mental effort in both years, because it requires a lot of attention from employees and a high work load per employee, because the hospital serves large volume patients daily, so there are a large amount of bills to be billed by the sector and established by the Health System to be achieved.

For both years, the work is considered complex and tiring, involving high responsibility related to the billing of hospital accounts, the work becomes stressful, 
because it requires a lot of mental effort from employees in the sector. In addition, in both years, employees have low autonomy and consequently work becomes more limited and less dynamic.

\subsubsection{Comparison Discomfort/Pain in the years 2018 and 2019}

Another analysis was related to Discomfort/Pain of employees, in order to point out possible relationships between the way the work was developed in 2018 and differences in the perception of workers after the changes made in the sector. For questionnaires related to Discomfort/Pain, values (or equals) to 0 considered low and values close (or equal) to 15 considered too much (very much), being for average responses greather than 7.5 indicative of EDIs that deserves attention, because they represent immediate intervention pains. Thus, similarly to that presented earlier, Table 2 was elaborated, which presents the means Discomforts/Pains for the years 2018 and 2019.

Table 2. Averages of Discomfort/Pain EDIs for the years 2018 and 2019.

\begin{tabular}{lcc}
\hline \multicolumn{1}{c}{ Discomfort/Pain } & Average EDI 2018 & Average EDI 2019 \\
\hline Arms & 6.7 & 8.4 \\
Hands & 8.3 & 7.8 \\
Legs & 6.6 & 7.3 \\
Feet & 5.5 & 5.9 \\
Back & 10.0 & 10.2 \\
Neck & 10.3 & 9.6 \\
Head & 10.0 & 9.5 \\
Stomach & 5.5 & 4.7 \\
\hline
\end{tabular}

According to the data presented in Table 2, it is pointed out that the worst Discomforts/Pains are in the back, neck, head and hands both in 2018 and in 2019. These four Discomforts/Pains have averages above 7.5 and should be considered for short-term intervention. Also, for 2019, pain/discomfort in the arms also has an average above 7.5. Studies such as [17] indicate that musculoskeletal pain may be associated with stressful work, as also pointed out in this study.

\section{Conclusions}

This transdisciplinary study is a collaboration between the disciplines of management (humanism) and ergonomics (in its macroergonomics approach). A study is conducted with billing staff at the University Hospital in the city of Curitiba - Paraná, Brazil, they are evaluated before and after changes in their workplace are implemented.

The participation of employees in the billing sector of a University Hospital in Brazil was the focus of the joint application of the macroergonomic approach and humanization. With the participation of employees, it became possible to find the requirements that needed improvement and thus, with their improvement, increase worker satisfaction. The use of the MAW participatory method helped to deepen workers' perceptions of the work they perform and in the identification of ergonomic demand indexes that lacked, and some still lack, improvements. MAW was fundamental for a diagnosis of the problems found in the sector, besides assisting in the identification and implementation of improvements.

From the results found, there was a $40.67 \%$ improvement in satisfaction with the computers suitability, as the new computers are more suitable for the activities carried out in the sector. There was also a $28.66 \%$ increase in workers' satisfaction with the change of the system used by the hospital. In addition to an $18.67 \%$ increase in the 
satisfaction of professionals in their relationship with other sectors / professionals, due to the change in the sector's management area.

The results of the two years indicate that workers in the sector have a high work load, are highly stressed, have a lot of responsibility, are highly tired, perform very repetitive and highly complex activities. The work done by the workers is considered to be not very creative and requires a lot of mental effort. In addition, in 2019, workers began to find work less stimulating, with a $10.67 \%$ reduction in this requirement compared to the previous year.

The results for the year 2019 also indicated that workers started to consider work much less dynamic (with a reduction of $26 \%$ compared to 2018) and much more limited (with an increase $22 \%$ compared to 2018). The term monotony is not understood by employees in 2018, but it started to be understood in 2019 after the changes made, since the difference between the two years is significant, of $20.66 \%$.

Finally, it is suggested that in future work the way the work process of the sector is conceived be evaluated, in order to make it less stressful, tiring, complex, repetitive, limited and monotonous, requiring less responsibility and psychological pressure on the part of the superiors, and thus more dynamic, creative and stimulating for workers, reducing their musculoskeletal pains (hands, arms, neck and back) and head. Also, it is suggested that other ergonomic evaluation methods be applied in order to solve the ergonomic demand indexes of the Environment construct and the physical space for work.

\section{References}

[1] L. B. DE M. Guimarães, Ergonomics: putting concepts into practice vol.1. 2. ed. Porto Alegre: Federal University of Rio Grande do Sul - Post-Graduation Program in Production Engineering, 1999.

[2] A. And. Michael, Pursuing Organization Integrity, In W. Amann and A. Stachowikz-Stanusch (eds.): Integrity in Organizations: Building the Foundations for Humanistic management, Palgrave Macmillan, 2013, pp. 19-39.

[3] ABERGO, 2018, International Definition of Ergonomics, Accessed: 21.02.2018. [Online]. Available: http://www.abergo.org.br/revista/index.php/ae/article/view/61/58.

[4] T. Kollman and A. Ertras. Transdisciplinary defining. The ATLAS T3 Bi-Annual Meeting Proceedings, vol. 1, The ATLAS Publications, USA, 2010, pp. 22-38.

[5] N. Wognum, C. Bil, F. Elgh, M. Stjepandic, W. Verhagen. Transdisciplinary Engineering Research Challenges, In Advances in Transdisciplinary Engineering, Vol. 7, 2018, pp. 753-762.

[6] D.Melé, The challenge of humanistic management, Journal of Business Ethics,44, 2003, pp. 77-88.

[7] M. A. Pirson and P. R. Lawrence, Humanism in business - Toward a Paradgm Shift?, Journal of Business Ethics, 93, 2009, pp. 553-565.

[8] I. Chyavenate, Administration - Theory, Process and Practice, 4. Ed., Elsevier, Amsterdam, 2007.

[9] IEA, International Ergonomics Association, 2019, What is ergonomics? Definition and applications. Accessed: 10.02.2020. [Online]. Available: https://www.iea.cc/whats/.

[10] I. Iida, Ergonomics: design and production. 2. ed. Blucher, São Paulo, 2005.

[11] H. W. Hendrick, The technology of ergonomics. Theoretical Issues in Ergonomics Science, v. 1, 2000, p. $22-33$.

[12] H. W. Hendrick, Applying ergonomics to systems: Some documented "lessons learned". Applied Ergonomics, 2008, Vol. 39, No. 4, pp. 418-426.

[13] H. Stone, J. Sidel, S. Oliver, A. Woolsey, R.C. Singleton, Senroty Evaluation by quantitative descriptive analysis. In: M.C. Gacula (eds.) Descriptive Sensory Analysis in Practice, https://doi.org/10.1002/9780470385036.ch1c.

[14] C. FRALEY, How Many Clusters? What Clustering Method? Answers Via Model-Based Cluster Analysis. The Computer Journal, 1998, Vol. 41, No. 8, pp. 578-588.

[15] A.M. Sasaki and L. by O.M. Leite, Macroergonomic Analysis of Work: Case Study in the Billing Sector of a University Hospital of Paraná. [s.1.] PUCPR - Pontifical Catholic University of Paraná, 2018.

[16] A. Wisner, Intelligence at work: selectedergonomictexts. Fundacentro, São Paulo, 1994.

[17] M. Barzideh, A.R. Choobineh, H. R. Tabatabaee, Job stress dimensions and their relationship to musculoskeletal disorders in Iranian nurses. Work, 2014, Vol. 47, No. 4, pp. 423-429. 